\title{
Special issue on engineering education: challenges for innovation
}

\author{
Gustavo R. Alves, Maria T. Restivo and Juarez B. da Silva
}

Engineering education plays an essential role in the pursuit of a more sustainable and equitable world. These two challenges imply training engineers to conceive and develop better goods and services with less, renewable resources (sustainability) for serving a large growing world population (equity), as denoted by the US National Academy of Engineering of the National Academies (2008). How to better train engineering students in a globalised, fast-evolving, and technology-dependant world is the goal of engineering education research.

During the past 100 years, a number of challenges in engineering education have been tackled by a worldwide community of researchers, either motivated by the emergence of new technologies contributing to or requiring a redefinition of engineering curricula or by the input of educational sciences with suggestions for new approaches to teaching \& learning (Froyd, Wankat, and Smith 2012). In all these shifts, innovation played a key role: either by improving a given aspect without compromising all remaining aspects (evolution) or by introducing a radically new aspect, often borrowed from other knowledge areas, allowing to improve a number of aspects at the same time (revolution).

The USA has shaped the landscape of engineering education for the past century, with associations like the American Society for Engineering Education (ASEE) now celebrating more than 120 years of existence. In contrast, Europe and Latin America have only embraced this movement in more recent decades, with associations like the European Society for Engineering Education (SEFI), the International Society for Engineering Pedagogy (IGIP), and the Brazil-ian Association for Engineering Education (ABENGE), being created in 1973, 1972, and 1973, respectively. More recently, the Portuguese Society for Engineering Education (SPEE) was formally created in 2010, in an endeavour to motivate, coordinate, and foster contributions from Portuguese researchers to the Engineering Education field.

This guest editorial is one particular result of that endeavour. It is structured as follows: Section 1 presents the very short history of SPEE, while also describing the antecedents of its 1st International Conference (CISPEE); Section 2 describes the rationale, aims, and layout of 
CISPEE, plus the process that led to the present special issue; Section 3 details the contents of the special issue and also of the special section, within a regular issue of the EJEE, containing a smaller number of contributions that required some additional editing efforts from their authors; and, finally, Section 4 concludes the guest editorial.

\section{The Portuguese Society for Engineering Education}

SPEE was launched and publicly presented in 19 February 2010, in a quite challenging period to all Higher Education Institutions (HEIs), in Europe, as a result of the implementation of the Bologna process and the economic crisis that led to deep public spending cuts in this sector. In Portugal, the situation was no less critical, but, spite of all difficulties, the 1st Management Board, led by Teresa Restivo, successfully gathered the interest and affiliation of the majority of the Portuguese Engineering Faculties and Schools, representing the whole country and its islands (Azores and Madeira), both the University and Polytechnic branches of the Portuguese HE system, and, finally, 200 individual founding members, the maximum stipulated in the Society bylaws.

To better understand the road map established by SPEE, one could read the words written by Costa (2011), rightfully acknowledged as the Society's initial mentor, in the first newsletter of SPEE: ' This new Society ... needs to gain dimension, as its success and sustainability depends upon this critical factor, ...' '. Again, according to Costa $(2011,5)$, this meant:

- Creating the conditions for sharing existing, and promoting the development of new knowledge necessary for advancing and innovating the area of engineering education;

- Involving a considerable number of HE teachers interested in Engineering Education, in Portugal;

- Seeking the Society's national and international recognition as an active and useful partner; and

- Guaranteeing the Society's financial sustainability.

Different initial actions taken by the 1st Management Board directly targeted these goals, namely: (i) the creation of a quarterly newsletter, edited in Portuguese, but also containing contributions, welcome and position statements written in English, especially from representatives of sister Societies (e.g. ASEE, IGIP, ABENGE, SEFI, the Institute of Electrical and Electronics Engineers (IEEE) Education Society, the Science and Education Research Council - COPEC, and the Ibero-American Association of Engineering Education Institutions - ASIBEI, as well as from other international colleagues); (ii) the creation of four working groups; (iii) the cooperation with international events by organising Special Tracks, (iv) supporting teachers development actions; and, (v) the call for organisers of the Society's 1st International Conference.

\section{The 1st International Conference of the Portuguese Society for Engineering Education}

The Polytechnic of Porto, through its School of Engineering (ISEP), responded positively to the call and was officially selected as the conference organiser in the SPEE General Assembly (GA) of April 2012.

Being the 1st edition, the organisers built a structure for the conference, in close cooperation with the new Management Board, also elected in the same GA. This structure observed the following guidelines: 
- Conference leadership: two joint general chairs, one being the present Chairman of the SPEE Management Board and the other being the Head of the Organizing Institution (ISEP, in the case of CISPEE 2013);

- Conference technical and scientific coordination: two joint programme chairs, one being from the Organising Institution and one person having served/willing to serve in this condition from the previous/following conference edition, respectively. Being the 1st conference edition and because of the Society's recent history, no one fitted in any of these two conditions, so the past Chairwoman of the SPEE Management Board kindly accepted to take this role;

- One conference theme, plus conference topics aligned with those of the Society working groups;

- Opportunity for formal training (one pre-conference workshop delivered by a world leading expert in Engineering education);

- A number of invited keynotes delivered by national personalities, both having a relation to the conference theme; and

- Technical and poster sessions, best paper and best poster awards, social events as integral parts of the conference, etc.

On top of this, the organisation devoted much attention and effort to guaranteeing the highest quality and impact level of the conference. Several societies, like the IEEE, IGIP, ABENGE, SEFI, the Portuguese Engineers Association (OE), and the American Society for Civil Engineers (ASCE), technically co-sponsored the event. The conference proceedings were submitted for inclusion in the IEEE Xplore $@$ Digital Library. Finally, a number of journals agreed to either: (i) publish one or more selected article(s) presented at the conference, for example, the ABENGE's journal $^{1}$ and the OE's journal, ${ }^{2}$ both edited in Portuguese; (ii) publish a special issue dedicated to the event, comprising a number of selected articles, each one including about $30 \%$ of new material, for example, the IEEE Revista Iberoamericana de Tecnologías del Aprendizaje (IEEERITA) ${ }^{3}$ and the International Journal of Engineering Pedagogy (iJEP); ${ }^{4}$ and, finally, (iii) launch an open call for submissions to a special issue on the same conference theme, subject to a new double-blind review process, for example, the European Journal of Engineering Education (EJEE) ${ }^{5}$

\section{The special issue}

\subsection{Call, submission, reviewing, and quality improvement process}

The open call for contributions ${ }^{6}$ of the EJEE special issue dedicated to the CISPEE theme, that is, 'Engineering Education: Challenges for Innovation', received a total of 31 (2-page) extended abstracts. This was the first time EJEE implemented a two-stage submission process based on an initial extended abstract followed by a full paper, which led to some interaction between the guest editors, the Editor-in-Chief and his Assistant, and the technical staff responsible for the submission platform. This first stage included submissions from all five continents, with a major contribution from authors affiliated with Portuguese HEIs. ${ }^{7}$ Table 1 depicts the geographical distribution of the received abstracts, whereas Tables 2 and 3 show their division, considering the criterion of the main author having (not) participated in CISPEE, and considering the accept/reject criterion, respectively. Combining the two criteria, the result was 12 abstracts from authors who participated in the event being invited to submit a full paper version, and 9 from other authors, in a total of 21 (i.e. an initial rejection rate of $42 \%$ ).

Following this initial stage, 18 full papers were submitted for double-blind review by at least 3 independent reviewers, which meant 3 dropouts (i.e. 14\%). The review process entailed a total 
Table 1. Geographical distribution of submitted abstracts.

\begin{tabular}{lcccccc}
\hline \multicolumn{2}{c}{ Europe } & & & & & \\
\cline { 1 - 2 } PT & $/ \mathrm{PT}$ & Americas & Africa & Asia & Australia/Oceania & Total \\
\hline 17 & 10 & 4 & 1 & 1 & 3 & 36 \\
$47 \%$ & $28 \%$ & $11 \%$ & $3 \%$ & $3 \%$ & $8 \%$ & $100 \%$ \\
\hline
\end{tabular}

Table 2. Distribution of received abstracts considering the criterion of the main author having (not) participated in CISPEE.

\begin{tabular}{|c|c|c|c|c|c|c|c|}
\hline & \multicolumn{2}{|c|}{ Europe } & \multirow[b]{2}{*}{ Americas } & \multirow[b]{2}{*}{ Africa } & \multirow[b]{2}{*}{ Asia } & \multirow[b]{2}{*}{ Australia/Oceania } & \multirow[b]{2}{*}{ Tota } \\
\hline & PT & $/ \mathrm{PT}$ & & & & & \\
\hline CISPEE & 15 & 2 & 1 & 1 & 0 & 0 & 21 \\
\hline /CISPEE & 2 & 8 & 3 & 0 & 1 & 3 & 15 \\
\hline Total & 17 & 10 & 4 & 1 & 1 & 3 & 36 \\
\hline
\end{tabular}

Table 3. Distribution of abstracts submission considering the 'accept/reject' decision.

\begin{tabular}{|c|c|c|c|c|c|c|c|}
\hline & \multicolumn{2}{|c|}{ Europe } & \multirow[b]{2}{*}{ Americas } & \multirow[b]{2}{*}{ Africa } & \multirow[b]{2}{*}{ Asia } & \multirow[b]{2}{*}{ Australia/Oceania } & \multirow[b]{2}{*}{ Total } \\
\hline & PT & $/ \mathrm{PT}$ & & & & & \\
\hline Accept & 9 & 8 & 1 & 0 & 1 & 2 & 21 \\
\hline Reject & 8 & 2 & 3 & 1 & 0 & 1 & 15 \\
\hline Total & 17 & 10 & 4 & 1 & 1 & 3 & 36 \\
\hline
\end{tabular}

Table 4. Overview of the reviewers' recommendations regarding the 18 submitted fullpaper versions.

\begin{tabular}{|c|c|c|c|c|c|}
\hline Recommendation & $\mathrm{A}$ & $\mathrm{Mi}$ & $\mathrm{Ma}$ & $\mathrm{R}$ & Total \\
\hline Total & 7 & 36 & 9 & 17 & 59 \\
\hline Percentage (\%) & 12 & 44 & \multirow{2}{*}{\multicolumn{2}{|c|}{$44 \%$}} & 100 \\
\hline & \multicolumn{2}{|c|}{$56 \%$} & & & $100 \%$ \\
\hline
\end{tabular}

of 59 reviews, ${ }^{8}$ with an overall positive tendency in terms of the reviewers' recommendations, as illustrated in Table 4. This tendency mostly resulted from the percentage of the 'Minor revision' recommendation (44\%), whereas the percentage of the 'Reject' recommendation clearly exceeded that of the 'Accept' recommendation (29\% versus $12 \%$, respectively). With this in mind, three different recommendations were issued: (i) resubmit with 'Minor revision', for 8 contributions; (2) resubmit with 'Major revision', for 7 contributions; and (3) 'Reject', for 3 contributions.

As a result of these recommendations, the authors were able to take on board the reviewers' feedback and improve their contributions. Only one author decided to dropout, this resulting in 14 final revisions received for a 2nd review round, which followed a different strategy, that is, articles recommended for minor revision were reviewed by only two independent experts and those recommended for major revision were again reviewed by three independent experts. ${ }^{9}$ Table 5 provides an overview of this 2 nd round, ${ }^{10}$ with a clear tendency for quality improvement, that is, 79\% of both 'Accept' and 'Minor revision' recommendations. The final result was nine 
Table 5. Overview of the 2 nd review round regarding the 14 received final versions.

\begin{tabular}{|c|c|c|c|c|c|}
\hline Recommendation & A & Mi & $\mathrm{Ma}$ & $\mathrm{R}$ & Total \\
\hline Total & 22 & 8 & 2 & 6 & 38 \\
\hline Percentage (\%) & 58 & 21 & 5 & 16 & 100 \\
\hline & \multicolumn{2}{|c|}{$79 \%$} & \multicolumn{2}{|c|}{$21 \%$} & $100 \%$ \\
\hline
\end{tabular}

articles accepted, which form the EJEE special issue dedicated to CISPEE, three articles recommended for a 3rd and last revision, and two rejected. The three papers requiring an additional revision will form a special section within a regular EJEE issue.

\subsection{Contents}

The first article, ${ }^{11}$ authored by Malheiro et al., describes a one-semester project-based learning programme, implemented at the Polytechnic of Porto - School of Engineering (Portugal), which has been running since 2011, with a combination of local and foreign students, from different engineering fields. Authors claim that this integrated engineering education approach, involving project-based learning, the development of complementary skills, teamwork, and cross-cultural experience, helps to better prepare engineering students for their professional life. Authors also highlight the student success rate being 100\%, since the programme start (i.e. from 2011 till 2014).

The second article, authored by Spelt et al., addresses the challenging aspect of helping students to acquire better interdisciplinary thinking. Authors claim that their design-based research study allowed them to verify the students' successful acquisition of such skills and also to evaluate different aspects in the new learning environment. However, they also conclude that further research is still needed to validate and also optimise the whole instructional design approach.

The third article, authored by Killen, details an experiential class activity on innovation decision-making, involving more than 480 engineering students. Besides extensively describing the design, implementation and evaluation processes, the author also claims that her research study, combining three different types of learning into one single experiential activity, allowed extracting findings that may inspire other engineering educators.

The fourth article, authored by $\mathrm{Li}$, describes an application of project-based learning in a course on electronic technology, while trying to meet the novel requirements of industry. The author claims that students felt engaged in the learning process and got confidence in finding solutions.

The fifth article, authored by Salmisto and Nokelainen, compares two different learning methodologies (case-based learning and knowledge creation-based learning) applied in two different courses of a freshmen year in civil engineering. By analysing the empirical data obtained from both courses, authors claim that each methodology has its merits, performing differently according to the desired aim. If favouring better students' metacognitive skills in engineering education, then authors advocate applying the knowledge creation-based learning methodology.

The sixth article, authored by May, Wold, and Moore, describes an intercontinental collaboration involving engineering students from two HEIs, the use of interactive online role-play simulations and the need to acquire global competence skills. Authors claim that the applied technology-enhanced multicultural teaching and learning scenario allowed students to better recognise and adapt to cultural differences, and hence perform better in 'a global, economic, environmental, and societal context'. 
The seventh article, authored by Carr et al., discusses the level of mathematical competences exhibited by incoming engineers in two European countries (Ireland and Portugal), through a modified diagnostic test applied in two HEIs, one in each country. Authors claim that some of the pre-existing supporting measures for tackling mathematical deficiencies of students attending the Irish institution could explain the slightly better performance of those students, in a few specific mathematical areas, when compared to the engineering students attending the Portuguese institution. As a result, authors propose to intensify the already existent cross-collaboration in this domain.

Also addressing the mathematical competences of engineering students, the eighth article, authored by Wedelin et al., focuses on the topic of mathematical modelling. Authors apply a qualitative case-study approach to a course on mathematical modelling and problem-solving, to finally claim that students largely benefitted from the careful instructional design and didactical planning done on such course.

Finally, the ninth article, authored by Dominguez et al., shares the authors' findings in implementing peer-review activities with engineering students. The authors used an action research approach to build their study and gather sufficient critical information leading to a proposal of an improved methodology taking into account the encountered limitations.

\subsection{The special section contents (within a journal regular issue)}

As previously mentioned, the three papers recommended for revision after two review rounds, required additional editing efforts, from their authors, and thus will form a special section within a regular EJEE issue. ${ }^{12}$

The first article, ${ }^{13}$ authored by Pinho-Lopes and Macedo, compares collaborative versus cooperative teamwork modalities in project-based learning models, using data extracted from five course editions (of two different courses). They analyse the overall efficacy of the models to finally advocate the collaborative modality being more adequate.

The second article, authored by Duarte, Leite, and Mouraz, describes the Personal Responsibility Orientation to Self-Direction in Learning Scale (PRO-SDLS) adapted to Portuguese terms and conditions, and its use for measuring the influence of curricular activities on students learning autonomy, as perceived by 140 first-year engineering students. Based on the analysis results, authors confirm that learners' characteristics (motivation and self-efficacy) contribute more to learner autonomy than the teaching-learning transaction (control and initiative), as in the original PRO-SDLS validation.

Finally, the third article, authored by Alves et al., studies the relationship between Portuguese engineering students and the learning of mathematics. With a similar sample size, that is, 140 undergraduate students from a different Portuguese HEI, authors claim the results only identify differences in the type of course and not in gender.

\section{Conclusion}

As initially thought by the guest editors, this special issue aimed at complementing the 1 st International Conference of the Portuguese Society for Engineering Education (CISPEE2013), namely by presenting authors with an opportunity to further perfect their work. The review process has undoubtedly contributed to a quality improvement, as denoted by Tables 4 and 5, with authors benefitting from the reviewers' feedback. Although this process requires additional time, it prompts for more and better reflection and ultimately provides more valuable material to engineering education researchers. 
It was during the course of this edition that Froyd $(2013,374)$ published an editorial stating that roughly ' $80 \%$ of the papers published and manuscripts submitted to the IEEE Transactions on Education could be categorised as falling within the scholarship of Application', the two other areas being the scholarship of Integration and the scholarship of Discovery. It is therefore no surprise that almost all articles that form our special issue also fall within the scholarship of Application category.

As a final note, we would like to thank the EJEE Editor-in-Chief (Erik de Graaff) and all of our peers (both authors and reviewers) for their cooperation and effort in making out of this special issue one of the best contributions of SPEE to the Engineering Education community.

\section{Notes}

1. http://www.abenge.org.br/revista/index.php/abenge

2. http://www.ordemengenheiros.pt/pt/centro-de-informacao/publicacoes/revista-ingenium/

3. http://ieeexplore.ieee.org/xpl/RecentIssue.jsp?punumber $=6245520$

4. http://online-journals.org/i-jep

5. http://www.tandfonline.com/toc/ceee20/current

6. http://www.sefi.be/?p $=3479$

7. Regarding nationality, we considered the country of the main author's institutional affiliation.

8. $18 * 3+5$ additional reviews for disambiguation purposes.

9. An effort was made to guarantee that these experts were the same who did the 1 st review.

10. With a total of $7 * 2+7 * 3+3$ additional reviews for disambiguation purposes.

11. This contribution was already published in a previous regular issue and hence does not form part of the printed version of the present special issue. However, the virtual online version of the present special issue includes this contribution, thanks to the possibility of including hyperlinks.

12. Again, the virtual online version of the present special issue includes all these three contributions, thanks to the possibility of including hyperlinks.

13. Observing the review process of this particular paper, it is interesting to note that the 1st review round resulted in two 'reject' and two 'minor revision' recommendations, which caused the guest editors to propose a 'major revision'. The 2nd review round, done by three of the four previous reviewers, resulted in two 'accept' and one 'minor revision' recommendations. The 3rd and last review, done by one of the three previous reviewers resulted in an 'accept' recommendation. The interesting aspect comes from the evaluation evolution of the reviewer who participated in all the three review rounds, that is, from 'reject' to 'minor', and then to 'accept', with the final following comment 'The authors have delivered an excellent manuscript'.

\section{ORCID}

Gustavo R. Alves (i) http://orcid.org/0000-0002-1244-8502

Maria T. Restivo (1) http://orcid.org/0000-0003-1118-9331

Juarez B. da Silva (D) http://orcid.org/0000-0002-5604-0576

\section{References}

Costa, C. 2011. "Why SPEE." 1st Newsletter of the Portuguese Society for Engineering Education, 5. http://spee.org.pt/ index.php/newsletter/33-newsletter-n1-fevereiro-2011 (testimonial in Portuguese).

Froyd, J. E. 2013. "Editorial: A New Direction for the IEEE Transactions on Education: Part I. Developing Shared Understanding of the Scholarship of Application." IEEE Transactions on Education 56 (4): 373-376.

Froyd, J. E., P. C. Wankat, and K. A. Smith. 2012. "Five Major Shifts in 100 Years of Engineering Education." Proceedings of the IEEE 100 (Special Centennial Issue): 1344-1360.

US National Academy of Engineering of the National Academies. "NAE Grand Challenges for Engineering." Accessed May 3, 2015. http://www.engineeringchallenges.org. 